\title{
Arbor
}

\section{La Armada y la Administración Marítima}

\section{Sebastián Zaragoza Soto}

Arbor CLXXIII, 682 (Octubre 2002), 337-346 pp.

España depende en gran medida de la mar. Todos somos conscientes de que las actividades marítimas son una componente esencial de la economía nacional y de que la compleja Administración Marítima es un área de vital importancia para nuestra nación.

Este artículo resume la progresiva transformación que ha experimentado la Armada para adaptarse a sus actuales funciones como organismo colaborador de la Acción del Estado en la Mar, en temas donde antes era organismo responsable. $Y$ todo ello como consecuencia del proceso de descentralización de la Administración General, y de la orientación cada vez más específica de la Armada hacia sus cometidos en Seguridad y Defensa.

Todas las Comunidades Autónomas con costa, y hasta siete Ministerios, tienen competencias en diferentes áreas relacionadas con la actividad maritima; y la Armada, además de colaborar con todos ellos, continúa manteniendo la responsabilidad de proteger los intereses marítimos nacionales y el ejercicio de la soberanía y cumplimiento de las leyes en nuestras aguas jurisdiccionales.

\section{Introducción}

España es una nación que por su situación geográfica depende en gran medida de la mar. La actividad marítima es un componente esencial de la economía nacional; por mar se realizan alrededor del $83 \%$ de las importaciones y el 63\% de las exportaciones; nuestra industria de pesca está a la cabeza de las de Europa y entre las principales 
del mundo; casi el $20 \%$ del tráfico marítimo mundial pasa por el estrecho de Gibraltar, transportando 900 millones de toneladas, y 200.000 buques pasan al año por nuestras costas. Asimismo, la mayor parte de las industrias y empresas turísticas están asentadas en el litoral.

Todo esto justifica la importancia que la Administración Marítima, entendida como el conjunto de Organismos del Estado con competencias en asuntos de la mar, debe tener en nuestra nación.

No hace muchos años, la Administración Marítima era un área, dentro de la Administración General del Estado, en la que la Armada tenía amplias competencias. El tiempo ha ido orientando a la Armada, cada vez más, hacia los cometidos de Seguridad y Defensa en estrecha cooperación con nuestros aliados. La concentración del esfuerzo en esa dirección, junto con las tendencias descentralizadoras en la Administración han llevado a que distintos Ministerios hayan ido asumiendo, en temas de la mar, diferentes competencias que anteriormente ejercía la Armada. De esta forma, la Armada ha pasado a ser organismo colaborador en temas donde antes era organismo responsable.

\section{La Acción del Estado en la Mar}

Poco a poco, se han desarrollado una serie de convenios y acuerdos entre distintos Organismos de la Administración para distribuir competencias y regular la actividad marítima, que comprende aspectos tan diversos como el ejercicio de soberanía, la pesca, la vigilancia o las acciones policiales, la protección del medio ambiente marino, el control de la navegación y la seguridad, las cuestiones portuarias, el cumplimiento de acuerdos internacionales y el salvamento.

Toda este conjunto de actividades es lo que llamamos la Acción del Estado en la Mar, es decir, el ejercicio de la autoridad del Estado para que la actividad marítima se regule de acuerdo con la legalidad establecida y queden protegidos los intereses marítimos nacionales.

Según la Ley de Costas corresponde al Ministerio de Defensa, y por lo tanto a la Armada, la vigilancia militar de las costas y la vigilancia del cumplimiento de los convenios internacionales para preservar su entorno.

En este marco, la Armada es responsable de una serie de actividades relacionadas con los intereses nacionales, que se materializan en el cumplimiento de misiones -algunas específicas y otras en colaboración con otros Organismos del Estado- que le obligan a disponer de medios para contribuir a la Acción del Estado en la Mar. 


\section{La Armada y la Administración Marítima}

Actualmente, los Almirantes Jefes de las Zonas Marítimas son los responsables del ejercicio de la soberanía nacional y del control de las actividades marítimas en las aguas de su zona de responsabilidad.

Esta responsabilidad se materializa en una serie de acciones concretas, tales como velar por el cumplimiento de normas de salvaguarda de los aspectos que puedan afectar a la Defensa en su Zona Marítima, vigilar el cumplimiento de acuerdos, normas internacionales y Derecho Marítimo, proporcionar apoyo a la navegación marítima y aérea ante emergencias, ejercer el control del tráfico marítimo y, en general, proteger los intereses marítimos nacionales y hacer cumplir las leyes en su área de responsabilidad.

Para el cumplimiento de estos cometidos los Almirantes de las Zonas Marítimas cuentan con Fuerzas de vigilancia y con las Comandancias y Ayudantías Navales que radican en su demarcación, y que constituyen la herramienta necesaria para posibilitar el ejercicio de sus funciones. Pero además, en determinadas situaciones, la Armada debe colaborar, de forma ágil y eficaz, con otros Organismos que también tienen competencias sobre aspectos relacionados con nuestros intereses marítimos.

La Armada, hoy en día, se encuentra inmersa en un proceso de cambios en su Organización, que afectarán a su estructura territorial y a la forma y medios con los que contribuye a la Acción del Estado en la Mar.

La futura Organización de los Ejércitos y la Armada, basada en criterios funcionales, traerá consigo la desaparición de las Zonas Marítimas, y el espacio marítimo nacional será concebido de forma global, como unidad geoestratégica de entidad única. Esta concepción tiene un importante soporte en los medios de Mando y Control que posee la Armada, que le permiten la dirección centralizada y la ejecución descentralizada de las diferentes actividades navales.

Así, la actual Organización territorial de la Armada, se transformará en otra de carácter funcional en la que un mando único, el Almirante de Acción Marítima, con dependencia directa del Almirante Jefe del Estado Mayor de la Armada, será el encargado de dirigir la contribución de la Armada a la Acción del Estado en la Mar.

Este Almirante, además de dirigir las acciones de vigilancia marítima y presencia naval, será el encargado de las relaciones institucionales de la Armada con las Autoridades de la Administración del Estado que correspondan en el ámbito marítimo.

\section{La colaboración institucional de la Armada}

El Ministerio de Defensa, y por lo tanto la Armada, colabora con otros siete Ministerios y, cuando es necesario, con las Comunidades 
Autónomas costeras, en tareas de Administración Marítima para regular las actividades en el medio marino.

Este ámbito de colaboración institucional se puede sintetizar como sigue:

\section{Con el Ministerio del Interior}

La colaboración se encuadra en aspectos relativos a la seguridad en la mar, tales como tráfico de drogas, inmigración clandestina, crimen organizado o terrorismo.

Esta colaboración se presta a los Cuerpos y Fuerzas de Seguridad del Estado y se realiza básicamente con el Servicio Marítimo de la Guardia Civil (SMGC), que tiene asignadas misiones que se desarrollan en el mar territorial y, sólo excepcionalmente, fuera de éste.

Para evitar interferencias o solapes entre el SMGC y la Armada se ha determinado una distribución general de los cometidos, asignando a la Armada los siguientes:

- Presencia habitual en los caladeros de pesca nacionales para conocer las actividades que allí se realizan y servir como elemento disuasorio que evite el empleo de métodos ilegales.

- Inspección a bordo de pesqueros para comprobar el cumplimiento de la legislación pesquera.

- Adopción de medidas provisionales ante presuntas infracciones.

Estos cometidos se realizan en el Mar Territorial, en la Zona Económica Exclusiva y en la Zona de Protección Pesquera del Mediterráneo.

Las relaciones entre la Armada y el SMGC son fluidas y existe un oficial de la Armada destinado en la Subdirección de Operaciones de la Guardia Civil que actúa como oficial de enlace.

Se ha creado, además, un órgano de trabajo conjunto que ha abordado temas como:

- La elaboración de un proyecto de Orden Ministerial sobre régimen, abanderamiento y matriculación de embarcaciones del SMGC.

- La elaboración de un proyecto de Orden Ministerial relativo a habilitación del personal del SMGC para dotación y manejo de embarcaciones.

- Convenios de utilización de instalaciones de la Armada por el SMGC.

En este contexto de colaboración con los Cuerpos y Fuerzas de Seguridad del Estado, también se ha firmado por los Ministerios de Defensa e Interior un «Acuerdo de colaboración en el ámbito de la 
lucha contra el tráfico ilegal de drogas». En virtud de este acuerdo, el Ministerio de Defensa colabora, cuando sus misiones y capacidades se lo permiten, con medios e instalaciones de las Fuerzas Armadas en operaciones de apoyo a la Delegación del Gobierno para el Plan Nacional sobre Drogas.

\section{Con el Ministerio de Fomento}

La Armada colabora con el Ministerio de Fomento en materias de seguridad de la navegación, salvamento de vidas humanas, lucha contra la contaminación del medio marino, auxilios, remolques y salvamentos, y hallazgos y extracciones marinas, excepto aquéllas de carácter militar que son competencia exclusiva de la Armada.

Entre las responsabilidades de este Ministerio existen dos áreas de especial importancia para la Defensa que implican colaboraciones de la Armada:

- La ejecución de la Política de Defensa en cualquier aspecto que afecte a puertos, espacios marítimo-terrestres que son de propiedad estatal, y buques y medios de la Marina Mercante.

- El estudio, programación, ejecución y supervisión de las posibilidades que ofrecen los puertos y medios de la Marina Mercante para tener prevista una eventual aportación de medios a la Defensa Nacional.

Como muestra de colaboración entre la Armada y el Ministerio de Fomento, los Comandantes Navales pueden formar parte de los Consejos de Administración de las Autoridades Portuarias en puertos con marcado interés para la Defensa.

En cuanto a control del tráfico marítimo, existen unas fluidas relaciones de cooperación y comunicación entre la Dirección General de la Marina Mercante y la Armada.

También la Armada colabora con el Ministerio de Fomento en la elaboración de las normas de seguridad para el ejercicio de actividades subacuáticas.

\section{Con el Ministerio de Agricultura, Pesca y Alimentación}

En el ámbito del Ministerio de Agricultura, Pesca y Alimentación, el Ministerio de Defensa, y en su representación la Armada. colabora según el acuerdo sobre la Inspección y Vigilancia de las actividades relacionadas con la Pesca Marítima. 
Se tratan en este contexto distintos temas enfocados a cuestiones tan diversas como: optimizar la conservación de recursos pesqueros, conocer el estado de caladeros españoles o de interés para nuestra flota pesquera, garantizar el cumplimiento de los acuerdos internacionales suscritos por España y de la legislación en materia de pesca, efectuar el seguimiento de incidentes o sucesos extraordinarios en los caladeros, y colaborar en la asistencia y el apoyo a los pescadores.

Así, existen acuerdos entre la Armada y la Secretaría General de Pesca para la utilización de los patrulleros Alborán, Chilreu y Arnomendi, con dotación de la Armada, en tareas de vigilancia e inspección de pesca. En estas campañas embarcan habitualmente inspectores nacionales o comunitarios.

\section{Con el Ministerio de Hacienda}

En lo referente al Ministerio de Hacienda, la relación con la Armada se mantiene a través de la Dirección Adjunta de Vigilancia Aduanera (DAVA). Esta Dirección es responsable de la persecución y represión en todo el territorio nacional, aguas jurisdiccionales, alta mar y espacio aéreo español, de los actos e infracciones de contrabando.

Los buques de la DAVA tienen consideración de buques auxiliares de la Armada y existe una estrecha colaboración y coordinación para asegurar la eficacia de sus misiones.

Estos buques están autorizados a detener, efectuar registros y aprehender buques españoles o extranjeros que naveguen por aguas fiscales españolas, sospechosos de portar contrabando. Los movimientos de estos buques sospechosos o intervenidos deben ser comunicados a las Autoridades del Ministerio de Hacienda y a las de la Armada, pudiendo ser solicitada la colaboración de buques de guerra para este tipo de operaciones.

La colaboración con este Ministerio se extiende también a áreas como la formación de personal (por ejemplo en buceo) y a la emisión, por parte de la Armada, de patentes de navegación para sus embarcaciones.

\section{Con el Ministerio de Ciencia y Tecnología}

La principal colaboración de la Armada se desprende del Acuerdo del Consejo de Ministros de 27 de julio de 1988, en el que se aprobó la construcción del buque de Investigación Oceanográfica Hespérides, construido con cargo al Ministerio (entonces de Educación y Ciencia) y cuya dotación y mantenimiento corresponde a la Armada. El Hes- 


\section{La Armada y la Administración Marítima}

pérides, todos los años, efectúa diversas campañas de investigación oceanográfica y científica, incluyendo una en aguas antárticas.

Las actividades del Hespérides y del buque polar Las Palmas durante la Campaña Antártica, planificadas por el Ministerio de Ciencia y Tecnología en coordinación con el Estado Mayor de la Armada, se desarrollan anualmente con notable éxito, llevando a cabo diversos proyectos científicos y prestando apoyo logístico a las Bases Antárticas españolas Juan Carlos I y Gabriel de Castilla.

\section{Con el Ministerio de Educación y Cultura}

Existe un proyecto de acuerdo entre el Ministerio de Defensa y el de Educación y Cultura para preservar al patrimonio arqueológico submarino y realizar campañas con medios y recursos de ambos $\mathrm{Mi}$ nisterios para la prospección del suelo y subsuelo de las aguas jurisdiccionales, y para la localización, identificación y eventual extracción de pecios y cuantos bienes sumergidos puedan integrar el patrimonio histórico español.

En estas campañas, la Armada aporta buques de apoyo a buceadores, así como personal buceador cuando se considera conveniente.

\section{Con el Ministerio de Asuntos Exteriores}

La capacidad de la Armada para actuar en representación propia o del Ministerio de Defensa en foros nacionales o internacionales para acuerdos o convenios en el ámbito marítimo, se pone de manifiesto, entre otros temas, en la colaboración de la Armada con el Ministerio de Asuntos Exteriores.

La Armada tiene representación en la Comisión Internacional de ímites entre España y Portugal, en la Comisión Internacional de los rineos y en la Comisión Interministerial de Política Marítima Innacional, donde se estudian temas relacionados con el Derecho del - que afectan a los intereses marítimos nacionales.

\section{Con las Comunidades Autónomas}

El artículo 148 de la Constitución Española establece que las Comunidades Autónomas podrán asumir competencias, entre otras, en materias de pesca en las aguas interiores (ríos, lagos, aguas continentales y aquéllas situadas desde la línea que delimita el Mar Territorial hacia el interior). 
Las Comunidades Autónomas litorales han asumido en sus Estatutos de Autonomía la competencia exclusiva en materia de pesca, marisqueo $\mathrm{y}$ acuicultura en aguas interiores, $\mathrm{y}$ han constituido sus propios servicios de vigilancia.

Actualmente no existen convenios de colaboración entre Comunidades Autónomas y el Ministerio de Defensa que requieran la actuación o colaboración de la Armada en las aguas interiores nacionales.

\section{Otras formas de contribución}

Con independencia de lo anterior, la Armada cuenta con Organismos cuyas funciones tienen una estrecha relación con la Administración Marítima:

- El Instituto Hidrográfico de la Marina es un Organismo de interés público nacional e internacional. Su misión es velar por la seguridad de la navegación en cuanto a obtener y difundir la información náutica necesaria.

Esto incluye, como organismo técnico y científico, la ejecución de levantamientos hidrográficos y el estudio del relieve submarino en las costas y zonas marítimas, así como la publicación de cartas náuticas.

También realiza labores de observación y estudio de los campos magnético y gravitatorio terrestre.

El Instituto Hidrográfico representa al Estado español en la Organización Hidrográfica Internacional, y a la Armada en diversos organismos de carácter tanto nacional como internacional.

- El Real Instituto y Observatorio de la Marina es un centro científico de la Armada que, a su misión específica como observatorio astronómico y geofísico, une la de investigación en aquellos campos de la ciencia físico-matemática que se consideran de interés para la Armada.

Entre sus cometidos están la elaboración de los estudios técnicos y los cálculos relacionados con las Efemérides Astronómicas y la publicación de éstas, así como la adquisición, conservación, reparación y estudio de equipos cronométricos al servicio de buques de guerra, y la reparación, estudio y certificación del mismo material de los buques mercantes que le sea confiado a tal fin.

Es depositario del Patrón Nacional del tiempo, y laboratorio asociado al Centro Español de Metrología. 


\section{La Armada y la Administración Marítima}

- El Tribunal Marítimo Central y los Juzgados Marítimos Permanentes son Organismos dependientes del Almirante Jefe del Estado Mayor de la Armada que tienen competencias en el conocimiento y resolución de las reclamaciones por extracciones y salvamentos marítimos.

A raíz de la entrada en vigor de la Ley Reguladora de los Auxilios y Salvamentos, se ha constituido un grupo de trabajo para estudiar el traspaso al Ministerio de Fomento de estos Organismos.

\section{Conclusiones}

De la descripción general que se ha expuesto sobre las colaboraciones que en materia de Administración Marítima presta la Armada a otros Organismos de la Administración del Estado, se deduce que el marco de actuación es muy variado y que, sin una buena coordinación, podrían producirse solapes en los cometidos asignados a diferentes Organismos.

La coordinación es absolutamente necesaria para optimizar el rendimiento de los recursos puestos a disposición del Estado para gestionar la Administración Marítima, ya que los medios que se requieren para desarrollar los cometidos relacionados con la Acción del Estado en la Mar son costosos de obtener y mantener, y el personal que los utiliza está altamente cualificado y debe mantener un adiestramiento constante.

Dadas las particularidades del medio, la mar, la coordinación de cualquier operación a desarrollar en un único escenario con la participación de varios Organismos es compleja, pues se necesitan profundos conocimientos del medio, personal con experiencia, recursos materiales fiables, y uniformidad en procedimientos de trabajo.

Esta coordinación, que a alto nivel es interministerial y en ella se fijan normas y pautas de actuación en el ámbito de la legislación vigente, tiene que traducirse en normas operativas que agilicen la actuación coordinada en la escena de acción. Aunque no se pueden dictar normas concretas, al depender de las circunstancias específicas de cada caso, la acción debe estar basada en la unidad de Mando, en un conocimiento exacto y en tiempo real de la situación, y en la posibilidad de adoptar decisiones fundamentadas según se desarrollen los acontecimientos.

Como resumen, podemos sintetizar tres ideas generales:

- La Armada, además de ejercer sus propias responsabilidades permanentes en nuestros espacios marítimos de soberanía e in- 
terés nacional, participa de forma coordinada con otros Organismos del Estado en la Administración Marítima, proporcionando los medios que materializan su capacidad de actuación en este ámbito.

- La Armada se encuentra en fase de reorganización para adaptar su estructura a las exigencias del entorno y para optimizar la eficacia de los medios de que dispone para contribuir a la Acción del Estado en la Mar. Esta reestructuración se sustenta en la concepción de un espacio marítimo de entidad única y en la capacidad de dirección centralizada y ejecución descentralizada.

- Para obtener el máximo rendimiento de todos los recursos del Estado al servicio de la Administración Marítima, es necesaria una gran coordinación tanto a nivel general en los ámbitos ministeriales, donde se delimitan cometidos y competencias, como en el escenario de actuación, donde es necesario contar con unidad de Mando, exacto y actualizado conocimiento de la situación y toma de decisiones en el nivel, momento y lugar adecuados a cada situación particular.

Con estas ideas básicas, la Armada reafirma la importancia que concede a sus relaciones con el conjunto de Organismos implicados en las tareas de Administración en el Ambito Marítimo y compromete con decidida voluntad el mejor de sus esfuerzos en ese servicio a España. 


\section{LA MARINA CIENTÍFICA}

